\title{
A LINGUAGEM ESCRITA E COMO ELA É ABORDADA NOS ANOS INICIAIS
}

Daniela de Paulo Rodrigues, Gabriela Tais Bento Andreatta, Elisa Gomes Magalhães.

Universidade do Oeste Paulista, Curso de Licenciatura em Pedagogia, Presidente Prudente, São Paulo. E-mail: dani.rodrigue@hotmail.com

\section{RESUMO}

Este artigo deriva-se de uma monografia intitulada "A Produção de Textos nos anos iniciais do Ensino Fundamental como prática de formação do escritor competente", cujo principal objetivo é investigar e analisar as possibilidades de práticas de ensino utilizadas na produção de texto nos primeiros anos do ensino fundamental, considerando a necessidade de formar este escritor, portanto apresenta um breve histórico do ensino de produção de texto na escola, com o propósito de averiguar aspectos desse processo de ensino aprendizado. Discutem-se alguns pressupostos teóricos que foram elencados nos Parâmetros Curriculares Nacionais de Língua Portuguesa (1997) e seus desdobramentos teóricos presentes nas Orientações Curriculares do Estado de São Paulo (2008). Utilizou a pesquisa bibliográfica com caráter qualitativo. Observamos em destaque nas referências que analisamos o planejamento, execução e avaliação de propostas que contemplem o envolvimento do aluno em todo o processo de construção e revisão textual.

Palavras-chave: Linguagem Escrita; Produção de Textos; Escritor competente; Prática Pedagógica; Educação.

\section{THE WRITTEN LANGUAGE AND HOW IT IS DEALT IN THE EARLY YEARS}

\begin{abstract}
This article derives from a monograph entitled "Production of texts in the early years of primary education and practical training of competent writer" whose main objective is to investigate and analyze the possibilities of teaching practices used in text production in the early years elementary school, considering the need to form this writer, therefore presents a brief history of the text production of teaching in the school, in order to investigate aspects of the teaching learning process. It discusses some theoretical assumptions that were listed in the National Curriculum Standards for Portuguese language (1997) and its theoretical developments present in the curriculum guidelines of the State of São Paulo (2008). Used the bibliographic research with qualitative. We note highlighted in the references we reviewed the planning, implementation and evaluation proposals that enhance student engagement throughout the construction and textual review process.
\end{abstract}

Keywords: Written language; Production Texts; competent writer; Teaching Practice; Education. 


\section{INTRODUÇÃO}

A linguagem escrita é o meio de comunicação mais utilizado depois da linguagem oral. No entanto, é por meio dela que a humanidade se comunica em seus vários espaços e se faz entender. Para que domine esse recurso às crianças são inseridas em práticas de leitura, assim, iniciando o processo formal de alfabetização escolar a partir de seis anos de idade e direcionadas a aprender a língua materna e suas particularidades. São utilizadas, nesse processo, atividades diversas, recursos e materiais pedagógicos que visam à promoção da aprendizagem dos estudantes como livros infantis, didáticos, filmes, e outros instrumentos que atuam como referência para que as crianças possam construir seu próprio conhecimento.

Este estudo é justificado por seu caráter científico e social devido à urgente necessidade de formação de um cidadão crítico e atuante na sociedade em que vive. Nesse sentido, torna-se cada vez mais relevante a proposição de estudos que contemplem o papel da leitura e da escrita na formação desse cidadão atuante. Assim, este estudo problematizou o papel da diversidade de gêneros textuais reais que circulam na sociedade na aprendizagem da escrita para que essa se tornasse mais contextualizada e significativa, formando escritores capazes de discorrer diante as várias estruturas sociais e de diversos temas. Desse modo, a escola precisa objetivar a formação de escritores competentes que saibam elaborar textos coerentes, utilizando recursos linguísticos, cognitivos e sociais. Nesse contexto, vislumbramos o ensino de diversos gêneros textuais como uma possibilidade de formação desse escritor competente.

O estudo teve por objetivo geral investigar e analisar as possibilidades das práticas de ensino de Produção de Textos nos anos iniciais do Ensino Fundamental considerando a necessidade da escola em formar o escritor competente e, como objetivos específicos, Investigar o processo de aprendizagem da linguagem escrita nos anos iniciais do Ensino Fundamental; Compreender as práticas de ensino de Produção de Textos que possibilitem a formação de um escritor competente de acordo com as Orientações Curriculares do Estado de São Paulo para Língua Portuguesa nos anos iniciais do Ensino Fundamental.

\section{METODOLOGIA}

A metodologia de pesquisa utilizada compreendeu uma abordagem de caráter qualitativo apoiada na pesquisa bibliográfica. Lakatos e Marconi (1992, p. 43) definem pesquisa bibliográfica como "levantamento de toda bibliografia já publicada, em forma de livros, revistas, publicações avulsas e imprensa escrita", a finalidade desta pesquisa foi fazer com que o escritor esteja diante de várias obras sobre um assunto específico. Foram utilizados livros que tratam de assuntos relacionados à formação de escritores competentes, autores que abordam práticas inovadoras e que consideram o trabalho da leitura e da escrita da criança.

Buscamos também analisar sobre metodologias de produção textual, com o embasamento em autores como Rosaura Soligo (2008), João Wanderley Geraldi (2006), Telma Ferraz Leal (2007), Kátia Leal Reis de Melo e Alexsandro da Silva (2007), as Orientações Curriculares do Estado de São Paulo, além dos Parâmetros Curriculares Nacionais de Língua Portuguesa, que por muito tempo serviu como referencial para a Educação Básica. Algumas das obras utilizadas são de abordagem sociointeracionista e incentivam a ensino da Produção Textual no contexto do aluno, fazendo com que o professor traga questões relacionadas ao contexto histórico, cultural e social para a realidade escolar. E a obra de Soligo (2008) tem o propósito de ampliar o conhecimento linguístico sobre os gêneros textuais, apresentando uma breve caracterização de alguns mais trabalhados na escola. As informações para a pesquisa bibliográfica foram coletadas por meio de leituras de algumas obras dos 
autores elencados, foram selecionados os conhecimentos relevantes para e sobre a discussão apresentada.

\section{RESULTADOS DA PESQUISA}

A pesquisa que realizamos evidencia que a aprendizagem da linguagem escrita em sala de aula se aparece alocada em práticas de escrita sem conexão com um projeto mais amplo, apresentada muitas vezes de forma fragmentada (BRASIL, 1997; SÃO PAULO, 2008; BRANDÃO; LEAL, 2007). A prática de produção de textos na escola tem sido na maioria das vezes realizada de forma superficial e sem estar integrada em um processo mais amplo que envolva a linguagem oral, a leitura e a prática da linguagem escrita.

Uma prática que conhecemos, portadora de tais características, são as chamadas sequências didáticas, que Zabala (1998, p.18) descreve como: "É um conjunto de atividades ordenadas, estruturadas e articuladas para a realização de certos objetivos educacionais, que têm um princípio e um fim conhecidos tanto pelo professor como pelos alunos", ou mesmo em projetos cuja a intenção é estimular a circulação da informação por meio de atividades integradoras, pois a função social da escola é incorporar o ser humano na sociedade, bem como a sociedade na escola.

Desde o momento em que a escrita passa a ser vista e trabalhada de maneira a agregar os escritos do mundo com os escritos da sala de aula, ela passa a fazer sentido e ser estimulada espontaneamente.

\section{DISCUSSÃO}

Sabendo que, depois da linguagem oral, a linguagem escrita é o meio de comunicação mais utilizado. Dessa forma, observamos o destaque da disciplina de Língua Portuguesa como um componente curricular facilitador de um trabalho que envolva o processo de alfabetização e letramento dos estudantes já nos anos iniciais do Ensino Fundamental. Nesse sentido, reconhecemos que nessas primeiras experiências escolares deve ser oferecido ao estudante condições para que ele compreenda o código linguístico da Língua Portuguesa e que saiba operá-lo intencionalmente para atingir seus objetivos por meio da escrita. Conforme observamos nas Orientações Curriculares do Estado de São Paulo (SÃO PAULO, 2008), os primeiros anos do Ensino Fundamental já apresentam expectativas que visam a autonomia da leitura e da escrita para cada estudante. $E$, durante, o processo de alfabetização o aluno já é estimulado a escrever textos mesmo quando ainda não está totalmente alfabetizado, ditando muitas vezes ao professor as ideias constituintes de sua organização mental de um texto. Esse procedimento é realizado coletivamente, com a colaboração dos demais colegas, em que há uma aprendizagem por colaboração, contando com a intervenção do professor a todo instante.

Conforme analisamos, historicamente após a alfabetização não eram usados recursos significativos que mobilizassem a produção de textos na escola como um processo contínuo. Era entendido como o saber desfrutar de uma escrita correta, cumprir as regras da gramática normativa e da ortografia. Os textos eram vistos como um agrupamento de palavras e frases, e que para serem escritos, bastava que os alunos aprendessem a escrever e logo depois de alfabetizados, aprendessem a unir frases gramaticais corretas, acreditava-se que a produção de textos só era possível a partir do domínio da escrita convencional, e assim permaneceu até meados do século $\mathrm{XX}$, preconizava as análises morfológicas e sintéticas (MARCUSCHI, 2010).

Na perspectiva sociointeracionista, a linguagem é o elemento primordial na aquisição de conhecimento sobre a Língua Portuguesa, pois tal concepção traz o conhecimento sistematizado que a criança vai adquirir ao longo da sua trajetória escolar dependente em partes, das práticas adotadas 
pelo professor e em partes, da relação social desta criança com o mundo que a rodeia. Percebe que produzir textos é uma atividade complexa, Brandão e Leal $(2007$, p.36) relatam que elaborar textos é um ato complexo e que desenvolve capacidades e conhecimentos "Produzir textos escritos é um ato complexo, pois envolve o desenvolvimento da capacidade de coordenar e integrar operações de vários níveis e conhecimentos diversos: linguísticos, cognitivos e sociais". Desse modo, para que haja veracidade na aprendizagem da escrita para uso social, é necessário aliar tais capacidades com vivencias reais envolvendo o uso da língua escrita:

Concebemos, de entrada, que, na escola, as atividades de produção de textos devem ser semelhantes às vivenciadas nos contextos extra-escolares. Parecenos necessário que, nessa instituição, os alunos escrevam em situações que se aproximem dos usos autênticos da escrita na sociedade, já que isso, certamente, dará mais sentido às atividades escolares de escrita de textos. (BRANDÃO; LEAL, 2007, p.33).

É uma discussão constante entre o que se quer escrever e qual a forma que tem que se escrever. Trata-se de um diálogo constante entre quem escreve o escrito e posteriormente com o interlocutor, gerando assim, em encontro linear entre os aspectos cognitivos e sociais, como salienta Ferraz et. al. (2010). Os PCN de Língua Portuguesa (BRASIL, 1997) apontam, para o primeiro ciclo do ensino fundamental, ou seja, para os anos iniciais, os conhecimentos que o aluno traz de casa como ponto de partida para o estudo com a linguagem. Leva em consideração que o aluno como ser humano começa seu processo de leitura de mundo desde quando nasce. Mesmo os adultos analfabetos têm uma experiência letrada, pois a sociedade se constitui de signos linguísticos e numéricos, a todo tempo nos deparamos com letras e números, códigos que representam diversos tipos de linguagem, sendo que as crianças também conhecem os significados e, ou, muitas vezes fazem suas próprias interpretações. Tendo em vista o conhecimento prévio da criança, o documento traz a importância de trabalhar o contexto dos alunos.

Por ser a linguagem de uso coletivo, existe uma preocupação que a instituição escolar, por ser o local da educação formal e ter como função social o ensino, assuma o aprendizado dos diferentes tipos de linguagem no convívio social, da mesma maneira que ela é tida fora da escola. Para tanto, os PCN (BRASIL, 1997) citam o agrupamento entre os estudantes como um método original, visto que a linguagem tem a finalidade da comunicação e a partir do momento em que se transmite algo a outro, ou seja, para que haja comunicação é preciso um remetente e um receptor. De modo bastante semelhante, as Orientações Curriculares do Estado de São Paulo (SÃO PAULO, 2008) sinalizam práticas para o trabalho com o gênero oral, escrito e a leitura, destacam-se neste documento a necessidade de tornar significativo o trabalho do aluno, agregando os conhecimentos da língua vividos na escola com aquele que é trazido do âmbito social/familiar e real.

Evidenciamos também um termo bastante profícuo para a discussão da importância da linguagem escrita nos anos iniciais cunhada na expressão "escritor competente" (BRASIL, 1997, p. 47): Um escritor competente é alguém que, ao produzir um discurso, conhecendo possibilidades que estão postas culturalmente, sabe selecionar o gênero no qual seu discurso se realizará escolhendo aquele que for apropriado a seus objetivos e à circunstância enunciativa em questão. Por exemplo: se o que deseja é convencer o leitor, o escritor competente selecionará um gênero que Ihe possibilite a produção de um texto predominantemente argumentativo; se é fazer uma solicitação a determinada autoridade, provavelmente redigirá um ofício; se é enviar notícias a familiares, escreverá uma carta. Um escritor 
competente é alguém que planeja o discurso e conseqüentemente o texto em função do seu objetivo e do leitor a que se destina, sem desconsiderar as características específicas do gênero.

Nesse sentido, nossa análise, primeiramente, aponta para a compreensão do papel da escola e da importância a que se deve atribuir ao processo de aprendizagem inicial da leitura e da escrita, componentes do que denominamos linguagem escrita. A escola, hoje, encontra o desafio de formar leitores competentes à medida que precisa adiantar-se com relação às propostas pedagógicas a serem oferecidas aos estudantes como possibilidade de aprendizagem da produção textual. $\mathrm{O}$ que destacamos, portanto, é algo que não pode ficar esquecido em um documento anterior (BRASIL, 1997), mas constitui-se como referencial metodológico aos professores dos anos iniciais nos dias de hoje: é preciso envolver os estudantes em processos de escrita que contemplem as necessidades reais da sociedade, ou seja, devemos nos preocupar em formar escritores competentes, pois serão esses os cidadãos que irão fomentar as práticas sociais de escrita na sociedade.

Apesar dos PCN (BRASIL, 1997) não se constituírem o referencial educacional atualmente, ele contempla objetivos relevantes se considerarmos que os pressupostos abordados naquele momento, ainda hoje nos permitem inferir sobre a necessidade de tornar a escola mais comunicativa do ponto de vista da formação de um leitor e um escritor crítico e atuante, ademais, as Orientações Curriculares do Estado de São Paulo (SÃO PAULO, 2008) nos aponta expectativas semelhantes quando observamos, em linhas gerais, a preocupação com a autonomia dos estudantes no processo de aprendizagem da leitura e da escrita. A esse respeito, as orientações encaminham as situações didáticas em sala de aula a partir de uma perspectiva que considere:

[...] Atividades para ensinar procedimentos de produção de textos (planejar, redigir rascunhos, reler, revisar e cuidar da apresentação); [...] Projetos didáticos ou seqüências didáticas em que os alunos produzam textos com propósitos sociais e tenham que revisar distintas versões até considerar o texto bem escrito, cuidando da apresentação final (SÃO PAULO, 2008, p.14).

Assim sendo, a escola necessita sempre retomar essa concepção sobre a formação que viabiliza aos estudantes, pois, atua na formação de cidadãos críticos e atuantes, sendo a escrita e leitura um dos maiores fatores de interação e transformação social. Para isso, são necessários conhecimentos reais das ações e dos instrumentos de atuação, ou seja, os objetivos da escrita e as formas de escrita.

Contudo, um fato que afasta os estudantes de uma boa escrita é a falta de conteúdo, para tanto, é fundamental um ambiente rico de gêneros textuais reais que podem ser encontrados na sociedade. E para que os alunos tenham acesso a todos os tipos de gêneros e principalmente aprendam escrever com quem já escreve: os autores de livros. Desse modo, é fundamental possibilitar práticas de leitura, para gerar conteúdo e servir como suporte na elaboração de textos consistentes.

Brandão e Leal (2007) consideram três aspectos primordiais na atividade de produzir textos: primeiro, as crianças são inseridas no universo da escrita ainda antes de escrever convencionalmente; segundo, a partir do momento em que o aluno conhece a escrita convencional e o sistema alfabético ele tem uma assimilação melhor de como funciona a estrutura de textos e compreende melhor os próprios conteúdos; terceiro, as autoras evidenciam que para cada situação da escrita o aluno utiliza de diferentes capacidades. Em vista desses aspectos, aliados com as atuais questões recorrentes do processo de ensino aprendizagem, vivenciados pelos professores nas salas de aula, bem como as 
dificuldades características aos alunos do ciclo um do ensino fundamental, dá se a importância do ensino da Produção de Textos, considerando que a escrita está inerente a socialização do ser humano.

\section{CONCLUSÃO}

Consideramos ao longo dessa pesquisa que para que ocorra a aprendizagem da leitura e da escrita nos anos iniciais do Ensino Fundamental, o trabalho pedagógico do professor precisa estar articulado a uma proposta mais ampla que considera a formação de um leitor e um escritor competente. A organização do trabalho é um elemento de grande importância na elaboração de uma produção textual eficiente, cabe então, ao professor planejar aulas, sendo o estudo por meio de projetos e sequência didática o mais indicado, para que essas aulas tenham o efeito esperado, tornase necessário a apresentação de vários gêneros textuais que proporcione aos alunos o conhecimento para a elaboração de diversos gêneros e tipos de texto. Entretanto percebe-se que não basta a informação estrutural de cada tipo de gênero textual, para que os educandos sintam interesse em aprender, deve haver uma relação com aquilo que ele vive no seu contexto social. E, observamos que esse processo metodológico envolve a organização de projetos e sequências didáticas em que o estudante se vê envolvido com a escrita e seu objetivo.

Compreende-se, por fim, que o processo de formação profissional docente, tanto inicial quanto continuada precisa oferecer condições para que professores e futuros professores vislumbrem seu papel na formação de um leitor e um escritor crítico e participativo, e assim sendo, deem sentido à necessidade de oferecer condições para que isso ocorra ao longo das aulas de Língua Portuguesa, no acesso aos diversos gêneros textuais presentes na sociedade atualmente. Dessa forma, com boas condições de ensino acreditamos que ocorra a aprendizagem da linguagem escrita de modo que o estudante possa fazer uso das competências aprendidas em sua vida social.

\section{REFERÊNCIAS}

BRANDÃO, Ana Carolina Perruci; LEAL, Telma Ferraz. (orgs.). Produção de textos na escola reflexões e práticas no Ensino Fundamental. Belo Horizonte: Autêntica, 2007.

BRASIL. Secretaria do Ensino Fundamental. Parâmetros Curriculares Nacionais: Língua Portuguesa. Brasília: MEC/SEF, 1998.

GERALDI, João Wanderley (orgs.). O Texto na Sala de Aula. 4ed. São Paulo: Ática, 2006.

LAKATOS, Eva Maria; MARCONI, Mariana de Andrade. Metodologia do Trabalho Científico. 4 ed. São Paulo: Atlas, 1992.

MARCUSCHI, Beth. Escrevendo na escola para a vida. In Rangel. E. O. e Rojo, R. H. (orgs.) Coleção explorando o ensino - Língua Portuguesa, Brasília, MEC, Secretaria de Educação Básica, 2010.

MELO, Kátia Leal Reis de; SILVA, Alexsandro da. Planejando o ensino de produção de textos escritos na escola. In: BRANDÃO, Ana Carolina Perruci; LEAL, Telma Ferraz. (orgs.).Produção de textos na escola reflexões e práticas no Ensino Fundamental. Belo Horizonte: Autêntica, 2007.cap. 5.

SÃO PAULO (ESTADO). Secretaria da Educação. Orientações Curriculares do Estado de São Paulo: Língua Portuguesa e Matemática - ciclo 1. São Paulo: FDE, 2008 
SOLIGO, Rosaura. Gêneros Textuais. Publicado parcialmente em outros Subsídios para Professores, p.1-41, 2008.

ZABALA, Antoni. A Prática Educativa: como ensinar. Porto Alegre: Editora Artes Médicas Sul Ltda., 1998. 